\title{
Experimental Study on Mechanical Properties and Seepage Laws of Raw Coal under Variable Loading and Unloading Rates
}

\author{
Kangwu Feng $\mathbb{D}^{\mathbb{D}},{ }^{1,2}$ Kequan Wang $\mathbb{D}^{2,3}$ Dongming Zhang $\mathbb{D}^{1},{ }^{1}$ and Yushun Yang $\mathbb{D}^{4,5}$ \\ ${ }^{1}$ School of Resources and Safety Engineering, Chongqing University, Chongqing 400044, China \\ ${ }^{2}$ Chongqing Institute of China Coal Research Institute, Chongqing 400037, China \\ ${ }^{3}$ State Key Laboratory of The Gas Disaster Detecting, Preventing and Emergency Controlling, Chongqing 400037, China \\ ${ }^{4}$ Faculty of Architecture and Civil Engineering, Huaiyin Institute of Technology, Huai'an 223001, China \\ ${ }^{5}$ State and Local Joint Engineering Laboratory for Gas Drainage \& Ground Control of Deep Mines, Henan Polytechnic University, \\ Jiaozuo 454003, China
}

Correspondence should be addressed to Yushun Yang; cqyysh@126.com

Received 10 April 2021; Accepted 20 September 2021; Published 19 October 2021

Academic Editor: Richeng Liu

Copyright ( 2021 Kangwu Feng et al. This is an open access article distributed under the Creative Commons Attribution License, which permits unrestricted use, distribution, and reproduction in any medium, provided the original work is properly cited.

\begin{abstract}
This manuscript studied the effects of variable axial pressure loading rate and variable confining pressure unloading rate on the deformation behavior and seepage characteristics of raw coal under alternate loading and unloading of axial pressure and confining pressure. It believed that as axial stress increases, axial strain $\varepsilon_{1}$ decreases, radial strain $\varepsilon_{3}$ increases, and permeability $k$ decreases, and $\varepsilon_{1}{ }^{\prime}, \varepsilon_{3}{ }^{\prime}$, and $k^{\prime}$ increase when confining pressure is decreases. With the loading of axial stress and the unloading of confining pressure, the variation amplitudes of $\varepsilon_{1}{ }^{\prime}, \varepsilon_{3}{ }^{\prime}$, and $k^{\prime}$ values reduce gradually. During axial stress loading, the rise in the amplitude of $\varepsilon_{1}$ is larger than that of $\varepsilon_{3}$ and the reduction in the amplitude of $k$, indicating that $\varepsilon_{1}$ is more sensitive to axial stress than $\varepsilon_{3}$ and $k$. During unloading of confining pressure, the increase rate of $\varepsilon_{3}$ is larger than that of $\varepsilon_{1}$ and $k$; also, $\varepsilon_{3}$ showed a high sensitivity to confining pressure. In the stage of axial stress loading and confining pressure unloading, the evolution law of deformation and permeability parameters is basically consistent with the change in loading and unloading rate.
\end{abstract}

\section{Introduction}

An abundance of coal resources with high stability in both mining and supply makes coal China's one of the most important energy resources. Due to the depletion of coal resource in the shallow strata, coal mining is gradually advancing to deep strata. The deep strata not only have complex geological conditions and are notoriously difficult to exploit, but are also in complex environments with high geostress, high permeation pressure, high ground temperature, and low permeability, which have an increased risk of coal and gas outburst, rock burst, and other mine dynamic disasters. Effective prediction and prevention of mine dynamic disasters at a technical level has become an area of focus for many researchers at home and abroad in recent years $[1-10]$.
In the process of coal mining, the excavation, well drilling, and hole drilling of coal seam and rock strata lead to changes in mining-induced stress and local stress concentration, resulting in deformation, instability, and failure of the coal and rock mass. In the process of coal seam excavation and driftage, methods for reducing excavation speed and cyclic excavation footage are commonly used to reduce the risk of deformation and failure of the coal and rock mass. Hence, the motivation behind research studies is to reduce the risk of mine dynamic disaster by changing the stress loading and unloading rates, which have an important effect on the mechanical properties and seepage characteristics of coal and rock masses. At present, scholars at home and abroad have conducted a lot of research on coal-rock mechanical properties under varying loading and unloading rate. 
Yin et al. [11] studied the effects of loading and unloading rates on dilatancy characteristics of sandstone under true triaxial stress and found that the dilatancy characteristics at the failure of sandstone were conspicuous when unloading rate increased, while the dilatancy point of sandstone gradually lagged behind, and the dilatancy capacity decreased when loading rate decreased. Xie et al. [12] used mining methods with three different loading and unloading rate ratios to analyze the mechanical properties of raw coal, and the results showed that the mining method of coal has a considerable impact on mining behavior characteristics. Lü and Qin [13] used an unloading confining pressure experiment on raw coal and found that increasing the unloading rate of confining pressure would significantly promote the deformation and failure of coal rock containing gas and reduce energy loss. Zhao et al. [14] studied the influence of loading and unloading rates on the mechanical and seepage properties of sandstone using cyclic loading and unloading, and the results showed that increasing number of cycles would increase the deformation modulus of sandstone, and the permeability followed the variation rule of " $\infty$." Wang et al. [15] studied the deformation and fracture characteristics of red sandstone at different strain rates and found that with increasing strain rate, the strength of the specimen first decreased and then increased, while the ratios of stress induced in the initiation and damage stress to strength when failure occurs always showed a decreasing trend. Jia et al. [16] carried out coal rock seepage test with reduced pore pressure and full stress-strain seepage test, constructed coal rock permeability model considering temperature stress, and discussed the evolution mechanism of coal rock gas seepage under the action of temperature and stress. Bai et al. [17] established the permeability model of damaged coal and rock under triaxial stress loading and unloading and verified the permeability model based on the test results. Li et al. [18] studied the AE waveform characteristics of rock mass under uniaxial loading based on Hilbert-Huang transform. Zhang et al. [19] studied the mechanical action mechanism of pore fluid on the preparation of coal and rock dynamic disasters under the disturbance of cyclic external load in different abutment pressure areas in front of mining. $\mathrm{Li}$ et al. [20] established the modified double $\mathrm{L}$ adsorption model and the coal rock permeability model considering the coupling effect of temperature and pore pressure and verified its rationality through the test results and test comparison.

The above studies are of great significance for accurately understanding of the influence of loading and unloading rates on the deformation and seepage characteristics of coal and rock masses. To further understand the influence of loading and unloading rates on the mechanical properties and permeability evolution law of raw coal, an experimental study is performed. The influence of variable axial loading rate and variable confining pressure unloading rate on the deformation, fracture, and permeability characteristics of raw coal under alternating axial and confining pressure loading and unloading is analyzed in this paper. The additional objective of the present research is to provide reliable suggestions for roadway support, design, and exca-
TABLE 1: The basic parameters of raw coal samples.

\begin{tabular}{lccc}
\hline No. & Diameter $(\mathrm{mm})$ & Height $(\mathrm{mm})$ & Weight $(\mathrm{g})$ \\
\hline S1 & 49.98 & 99.96 & 296.54 \\
S2 & 49.96 & 99.96 & 296.58 \\
S3 & 49.94 & 99.96 & 296.86 \\
S4 & 49.98 & 99.96 & 296.89 \\
S5 & 49.96 & 99.96 & 296.32 \\
S6 & 49.96 & 99.96 & 296.18 \\
S7 & 49.96 & 99.96 & 296.58 \\
S8 & 49.98 & 99.96 & 296.75 \\
\hline
\end{tabular}

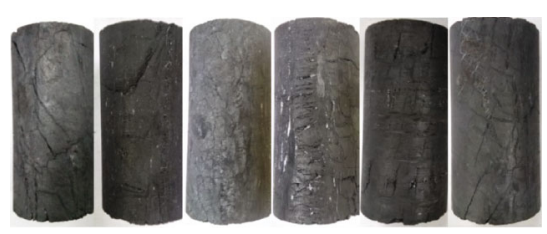

FIgURE 1: Standard raw coal specimens.

vation of chambers, as well as for surrounding rock stability analysis.

\section{Specimens and Test Scheme}

2.1. Preparation of Specimens. Raw coal specimens used in this test are taken from Shamushu Coal Mine of Sichuan Coal Industry Group. The block coal was processed into standard raw coal specimens with dimension of $\Phi 50 \times 100$ $\mathrm{mm}$ via laboratory processes. The end unevenness was controlled within $0.05 \mathrm{~mm}$, the basic parameters of raw coal samples are shown in Table 1, and the density of raw coal specimens was $1.513 \mathrm{~g} / \mathrm{cm}^{3}$. The raw coal specimens are shown in Figure 1.

2.2. Test Apparatus. The apparatus used in the test is a thermal-fluid-solid coupling seepage device for coal and rock containing gas independently developed at Chongqing University [21], as is shown in Figure 2. The system consists of a loading control system, stress and strain acquisition and analysis system, internally sealed seepage system, and acoustic emission monitoring system. The test system can perform experiments on specimens with a size of $(\varphi 50 \times 100 \mathrm{~mm})$ and $(\varphi 100 \times 200 \mathrm{~mm})$ and can provide maximum axial pressure of $1000 \mathrm{kN}$, maximum confining pressure of $60 \mathrm{MPa}$ in radial direction, and maximum gas pressure of $6 \mathrm{MPa}$. The system is capable of conducting experimental tests of failure, seepage, and hydrofracture under coupled multiple mininginduced stress paths, gas pressure, and temperature.

2.3. Testing Program. The raw coal specimen is placed in the loading chamber. Axial stress $\sigma_{1}$ and confining pressure $\sigma_{3}$ are loaded at a loading rate of $0.2 \mathrm{kN} / \mathrm{s}$ up to hydrostatic pressure of $7 \mathrm{MPa}$, and $\mathrm{CH}_{4}$ gas at $2 \mathrm{MPa}$ is then passed through the inlet. The test is carried out after the coal specimen absorption lasts for 2 hours, and the outlet flow is 

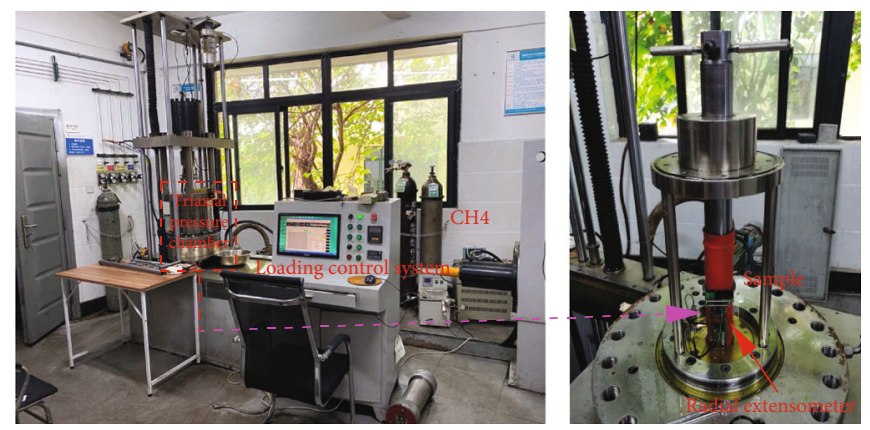

FIGURE 2: Thermal-fluid-solid coupling seepage apparatus for coal and rock containing gas.

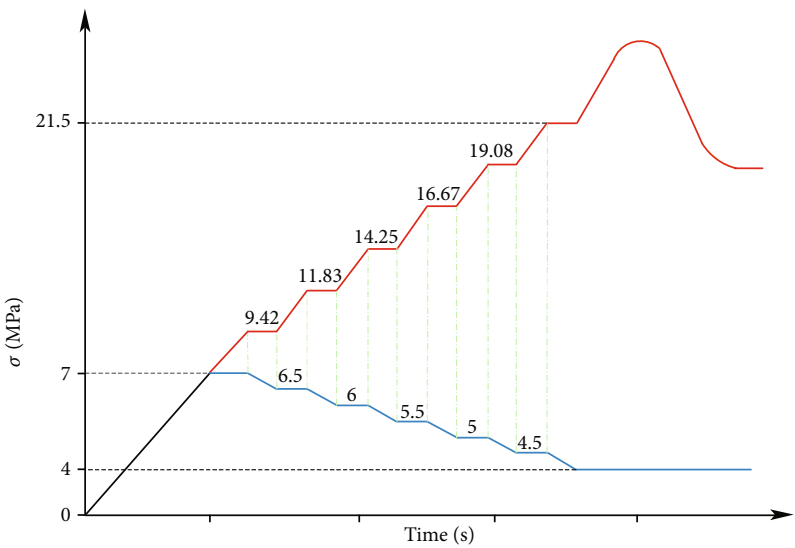

FIGURE 3: Alternate loading and unloading paths.

TABLE 2: Testing program of variable loading and unloading rates under alternate loading and unloading paths.

(a) Variable axial pressure loading rate path (specimens S1-S4)

\begin{tabular}{lcccccc}
\hline \multirow{2}{*}{ Axial pressure (MPa) } & \multicolumn{9}{c}{ Loading rate of axial pressure $(\mathrm{kN} / \mathrm{s})$} & Confining pressure (MPa) & $\begin{array}{c}\text { Unloading rate of confining } \\
\text { pressure }(\mathrm{kN} / \mathrm{s})\end{array}$ \\
\hline 7 & $\mathrm{~S} 1$ & $\mathrm{~S} 2$ & $\mathrm{~S} 3$ & $\mathrm{~S} 4$ & 7 & 0.02 \\
9.42 & & & & & 6.5 & 0.02 \\
11.83 & 0.01 & 0.5 & 0.01 & 0.5 & 6 & 0.02 \\
14.25 & 0.02 & 0.2 & 0.05 & 0.2 & 5.5 & 0.02 \\
16.67 & 0.05 & 0.1 & 0.2 & 0.05 & 5 & 0.02 \\
19.08 & 0.1 & 0.05 & 0.5 & 0.01 & 4.5 & 0.02 \\
21.5 & 0.2 & 0.02 & 0.2 & 0.05 & 4 & \\
\hline
\end{tabular}

(b) Variable confining pressure unloading rate path (specimens S5-S8)

\begin{tabular}{|c|c|c|c|c|c|c|}
\hline \multirow[t]{2}{*}{ Axial pressure $(\mathrm{MPa})$} & \multirow[t]{2}{*}{ Loading rate of axial pressure $(\mathrm{kN} / \mathrm{s})$} & \multirow[t]{2}{*}{ Confining pressure (MPa) } & \multicolumn{4}{|c|}{$\begin{array}{l}\text { Unloading rate of confining pressure } \\
\qquad(\mathrm{kN} / \mathrm{s})\end{array}$} \\
\hline & & & S5 & S6 & S7 & S8 \\
\hline 7 & & 7 & & & & \\
\hline 9.42 & 0.05 & 6.5 & 0.001 & 0.05 & 0.002 & 0.05 \\
\hline 11.83 & 0.05 & 6 & 0.002 & 0.02 & 0.005 & 0.02 \\
\hline 1425 & 0.05 & 55 & 0.005 & 0.01 & 0.02 & 0.005 \\
\hline 14.25 & 0.05 & 5.5 & 0.01 & 0.005 & 0.05 & 0.002 \\
\hline 16.67 & 0.05 & 5 & 0.02 & 0.002 & 0.02 & 0.005 \\
\hline 19.08 & 0.05 & 4.5 & 0.05 & 0.001 & 0.005 & 0.02 \\
\hline 21.5 & & 4 & & & & \\
\hline
\end{tabular}




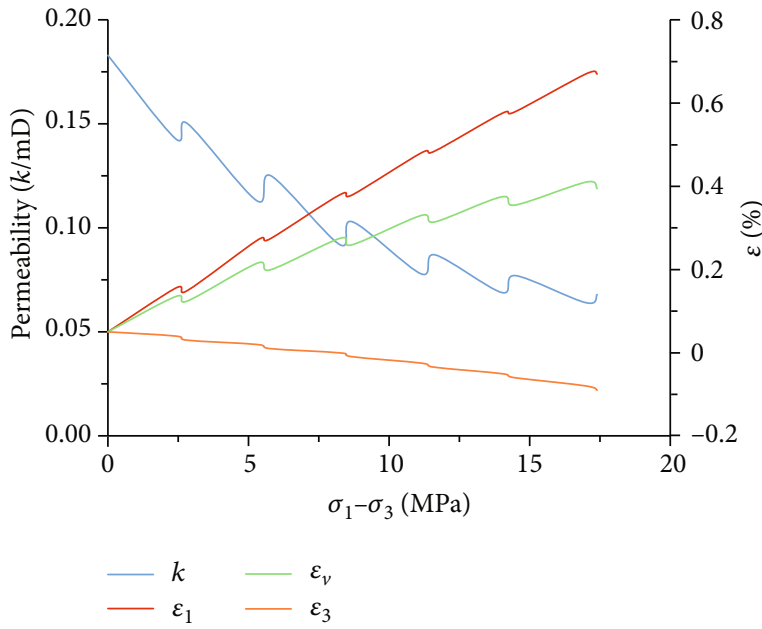

(a) Stress-strain-permeability curve of raw coal specimen S1

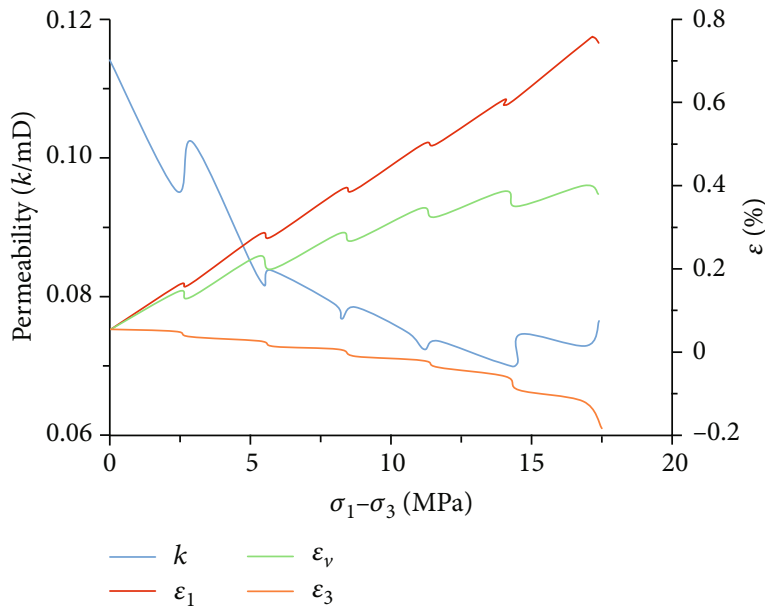

(c) Stress-strain-permeability curve of raw coal specimen S3

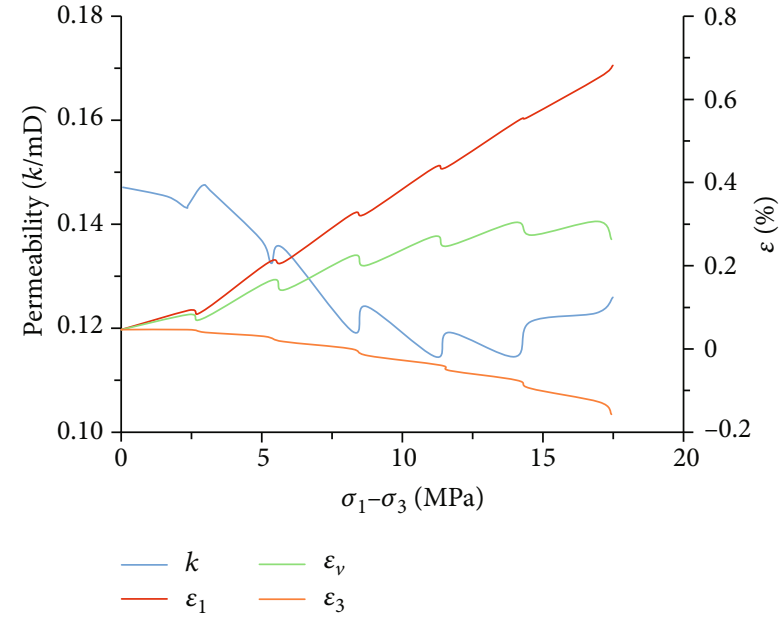

(b) Stress-strain-permeability curve of raw coal specimen S2

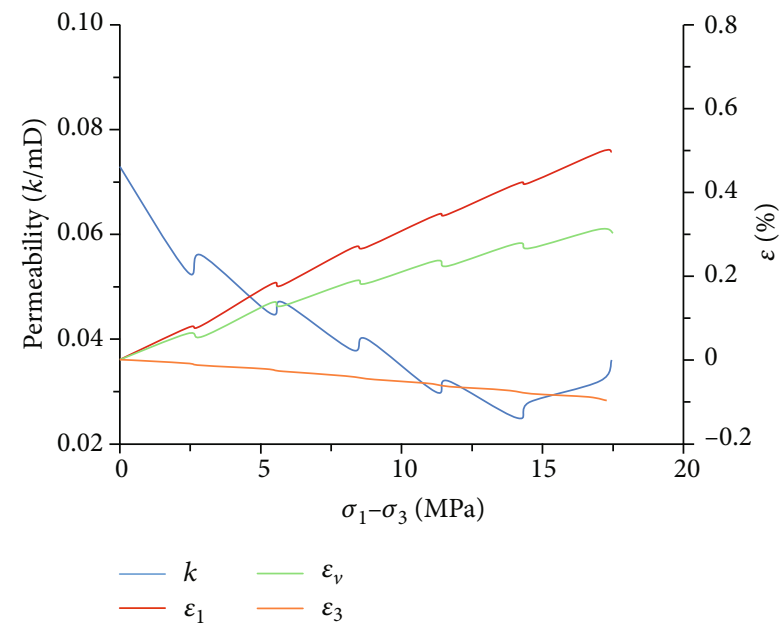

(d) Stress-strain-permeability curve of raw coal specimen S4

Figure 4: Stress-strain-permeability curve of raw coal under variable axial pressure loading rate.

stable. The test loading program is shown in Figure 3. In this test, alternately loading axial pressure $(2.42 \mathrm{MPa})$ and unloading confining pressure $(0.5 \mathrm{MPa})$ are adopted to change the axial pressure loading rate and confining pressure unloading rate, respectively, to explore their influence on the deformation and permeability characteristics of raw coal. The specific loading rates of the test are summarized in Table 2. After the axial pressure loading and confining pressure unloading reach the specified target value, the loading mode is changed to displacement controlled loading, with a loading rate of $0.00167 \mathrm{~mm} / \mathrm{s}$, until the raw coal specimen is damaged. During loading and unloading, a mass flowmeter is used to monitor the gas flow at the outlet, and Darcy's law is employed to calculate the permeability of raw coal specimen at different loading and unloading rates which is given as follows $[17,21]$ :

$$
k=\frac{2 q \mu L P_{2}}{A\left(P_{1}^{2}-P_{2}^{2}\right)},
$$

where $k$ is permeability of raw coal specimen, $\mathrm{m}^{2} ; L$ is length of raw coal specimen, $\mathrm{m} ; q$ is gas flow under standard conditions, $\mathrm{m}^{3} / \mathrm{s} ; \mu$ is dynamic viscosity of gas, $\mathrm{Pa} \cdot \mathrm{s} ; A$ is cross section area of raw coal specimen, $\mathrm{m}^{2} ; P_{2}$ is ambient pressure, $\mathrm{MPa} ; P_{1}$ is inlet end gas pressure, $\mathrm{MPa}$.

\section{Test Results and Analysis}

3.1. Analysis of Stress-Strain Permeability Curve under Variable Axial Pressure Loading Rate. Under alternating loading and unloading conditions, the stress-strainpermeability curve of raw coal specimen under a variable axial pressure loading rate is shown in Figure 4 . The permeability of specimen S4 is small during the test, and no considerable change rule can be observed; therefore, the evolution of permeability of this specimen is ignored. Each increment of axial stress by $2.42 \mathrm{MPa}$ leads to an increase in axial strain $\varepsilon_{1}$ and radial strain $\varepsilon_{3}$ as well as a decline in permeability $k$. This is because increasing of axial stress causes axial compression deformation and radial expansion 


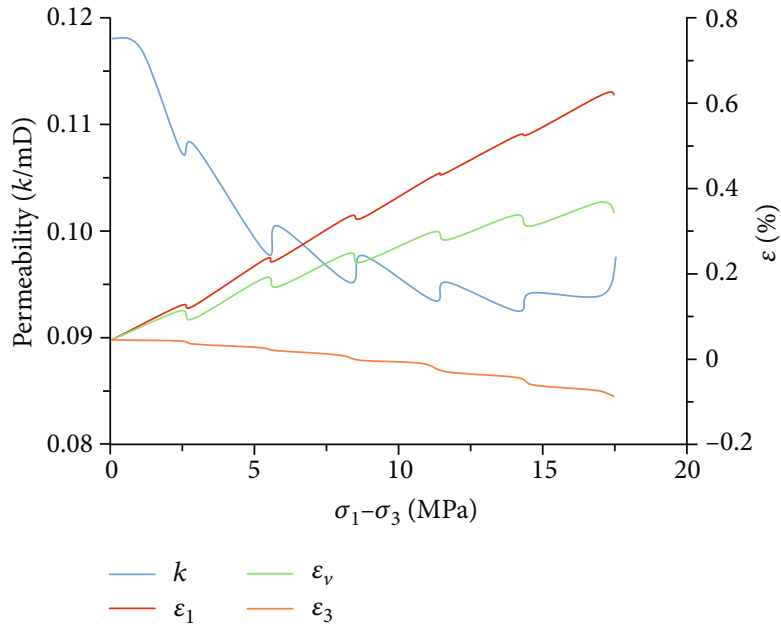

(a) Stress-strain-permeability curve of raw coal specimen S5

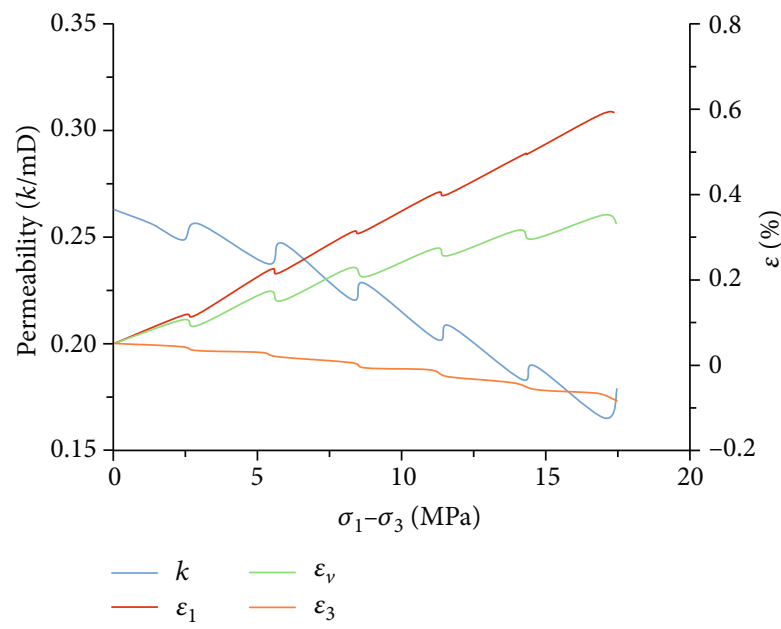

(c) Stress-strain-permeability curve of raw coal specimen S7

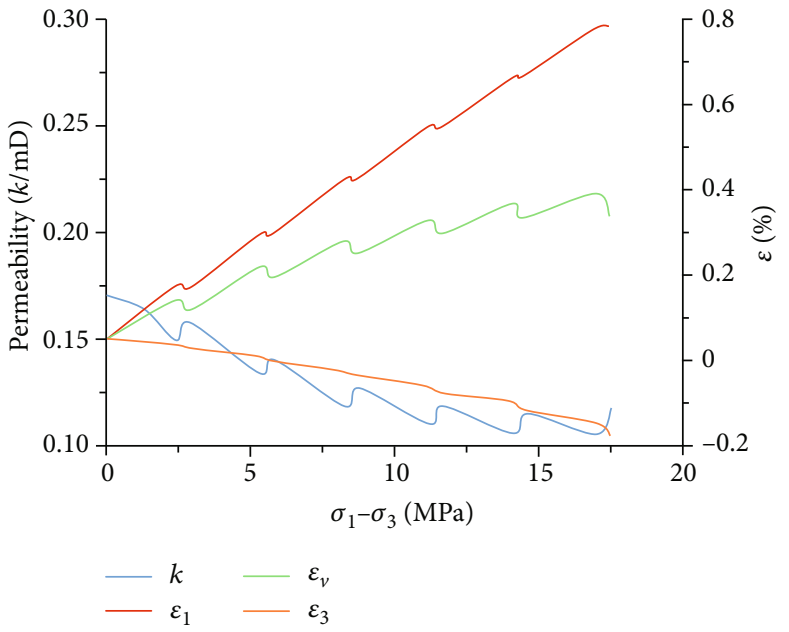

(b) Stress-strain-permeability curve of raw coal specimen S6

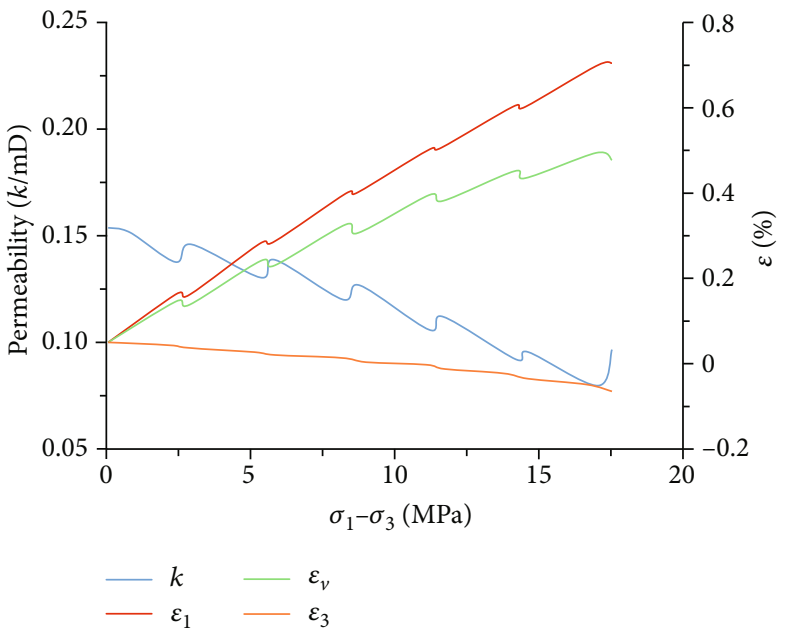

(d) Stress-strain-permeability curve of raw coal specimen S8

FIGURE 5: Stress-strain-permeability curve of raw coal under variable confining pressure unloading rate scheme.

of raw coal specimen, which increases both axial and radial strains. The pore cracks in raw coal are compressed, and the seepage channel is narrowed, leading to the decline of permeability. When confining pressure decreases by $0.5 \mathrm{MPa}, \varepsilon_{1}, \varepsilon_{3}$, and $k$ increase. This can be attributed to the fact that confining pressure unloading causes radial expansion of raw coal specimen, increase of $\varepsilon_{1}$, increase of pore crack area in raw coal, relative reduction of crack tortuousness, and expansion of gas seepage channels, thus eventually showing increase of permeability. With the loading of axial stress and the unloading of confining pressure, the variation amplitudes of $\varepsilon_{1}, \varepsilon_{3}$, and $k$ all decrease gradually. In the process of axial force loading, the increased amplitude of $\varepsilon_{1}$ is larger than that of $\varepsilon_{3}$ and the decreased amplitude of $k$, indicating that $\varepsilon_{1}$ is more sensitive to axial stress than $\varepsilon_{3}$ and $k$. However, $\varepsilon_{1}$ has a small variation amplitude during confining pressure unloading, showing a low sensitivity to the confining pressure. Similarly, during confining pressure unloading, the increased amplitude of $\varepsilon_{3}$ is larger than that of $\varepsilon_{1}$ and $k$, and $\varepsilon_{3}$ shows a higher sensitivity to the confining pressure.
The axial strain is represented by $\varepsilon_{1}$, the radial strain is represented by $\varepsilon_{3}$, the volumetric strain is represented by $\varepsilon_{v}$, and the calculation formula is as follows:

$$
\begin{gathered}
\varepsilon_{1}=\frac{\Delta L}{L}, \\
\varepsilon_{3}=\frac{\Delta D}{\pi D}, \\
\varepsilon_{v}=\varepsilon_{1}+\varepsilon_{3},
\end{gathered}
$$

where $\Delta L$ is the axial deformation, $\mathrm{mm} ; L$ is the height of the sample, $\mathrm{mm} ; \Delta D$ is radial deformation, $\mathrm{mm} ; D$ is the diameter of the sample, $\mathrm{mm}$.

With the change from axial loading mode to displacement loading, the increased amplitude of $k$ for specimen $S 1$ first decreases and then increases, and the increased amplitudes of $k$ for specimens S2 and S3 gradually increase until the specimens are damaged. When raw coal specimens are damaged, the peak strength is $40.39 \mathrm{MPa}$ for specimen 


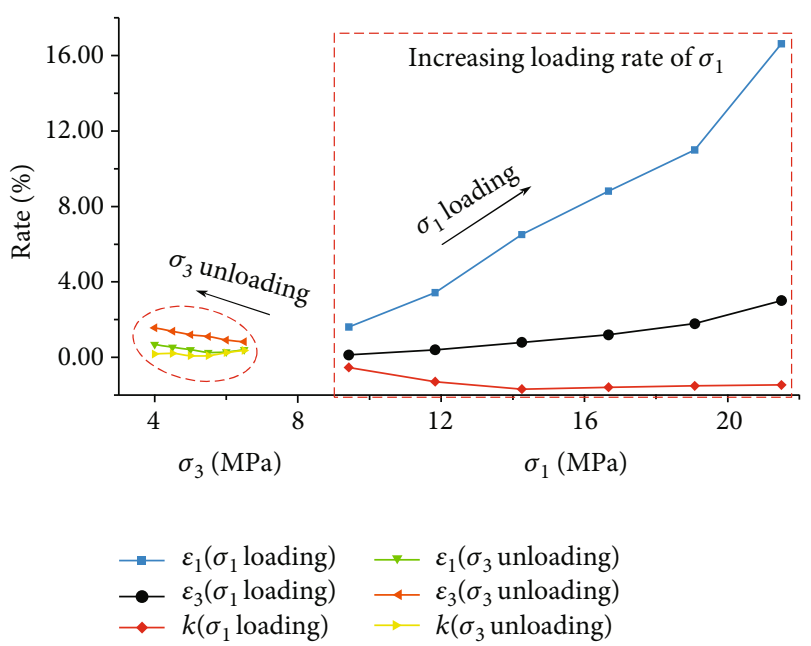

(a) Rate of change of strain and permeability of raw coal specimen S1

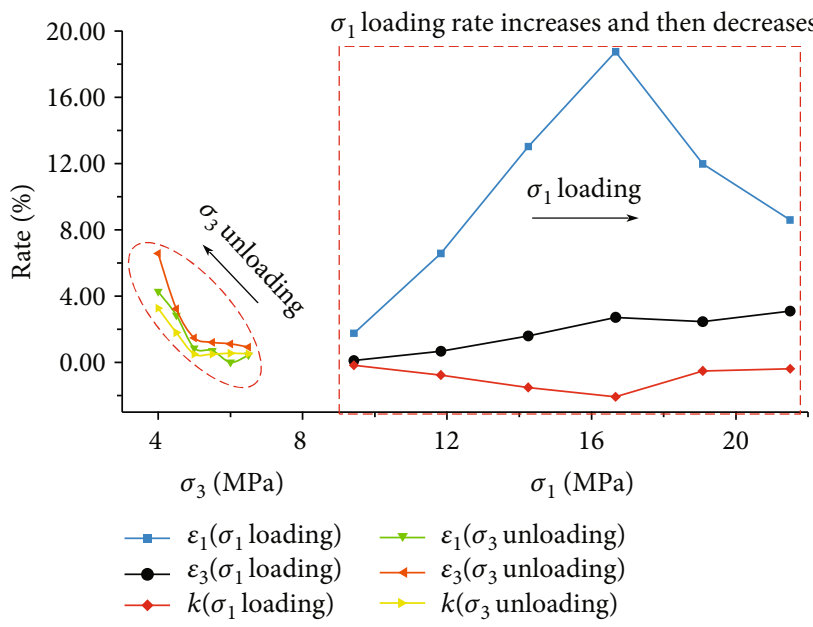

(c) Rate of change of strain and permeability of raw coal specimen S3

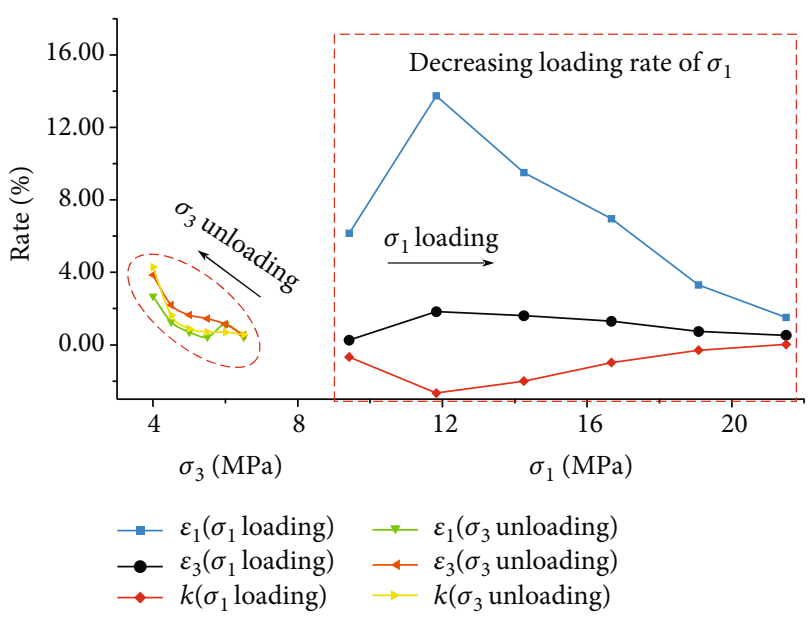

(b) Rate of change of strain and permeability of raw coal specimen S2

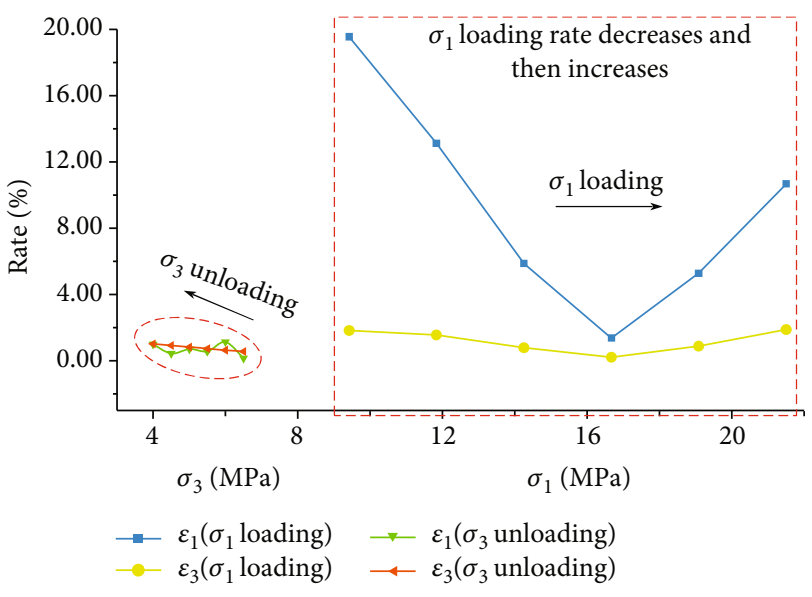

(d) Rate of change of strain and permeability of raw coal specimen S4

FIGURE 6: Rate of change of strain and permeability of raw coal under variable axial pressure loading rate scheme.

$\mathrm{S} 1,26.66 \mathrm{MPa}$ for specimen 2, 36.25 $\mathrm{MPa}$ for specimen $\mathrm{S} 3$, and $46.61 \mathrm{MPa}$ for specimen $\mathrm{S} 4$. The strength anisotropy is due to the initial microcracks within the raw coal specimen in different directions caused by the change of axial loading rate, as well as the anisotropy of coal sample's own structure (stratification and cleat structure), resulting in a great difference in strength.

\subsection{Analysis of Stress-Strain Permeability Curve at Variable} Unloading Rate under Confining Pressure. Under alternate loading and unloading conditions, the stress-strainpermeability curves of raw coal specimen under variable confining pressure unloading rate are shown in Figure 5. When the axial stress increases by $2.42 \mathrm{MPa}$ and the confining pressure decreases by $0.5 \mathrm{MPa}$, the variation of axial strain, radial strain, and permeability shows similar patterns to those shown in Figure 4. With the loading of axial stress and the unloading of confining pressure, the variation amplitudes of $\varepsilon_{1}$ and $\varepsilon_{3}$ decrease gradually. However, the variation amplitude of $k$ shows a different trend. During alternating loading and unloading, $k$ shows an alternating increasing and decreasing pattern, and simultaneously, it shows an overall downward trend as a whole. In the same axial loading process, the increased amplitude of $\varepsilon_{1}$ is greater than that of $\varepsilon_{3}$ and the decreased amplitude of $k$, and $\varepsilon_{1}$ is more sensitive to axial stress and less sensitive to confining pressure. In the unloading process of confining pressure, the increased amplitude of $\varepsilon_{3}$ is larger than that of $\varepsilon_{1}$ and $k$ in the unloading process of confining pressure, and $\varepsilon_{3}$ is more sensitive to confining pressure. The peak strength values of raw coal specimens S5-S8 are $56.60 \mathrm{MPa}$, 33.19 $\mathrm{MPa}, 42.09 \mathrm{MPa}$, and 43.23 $\mathrm{MPa}$, respectively, when they are damaged. The initiation and propagation of initial microcracks and the anisotropy of coal sample structure lead to the difference in raw coal strength.

\section{Discussions}

4.1. Effects of Variable Axial Loading Rate on Strain and Permeability. To explore the evolution laws of axial strain $\varepsilon_{1}$, radial strain $\varepsilon_{3}$, and permeability $k$ of raw coal under the condition of variable of the axial loading rate, formulas 


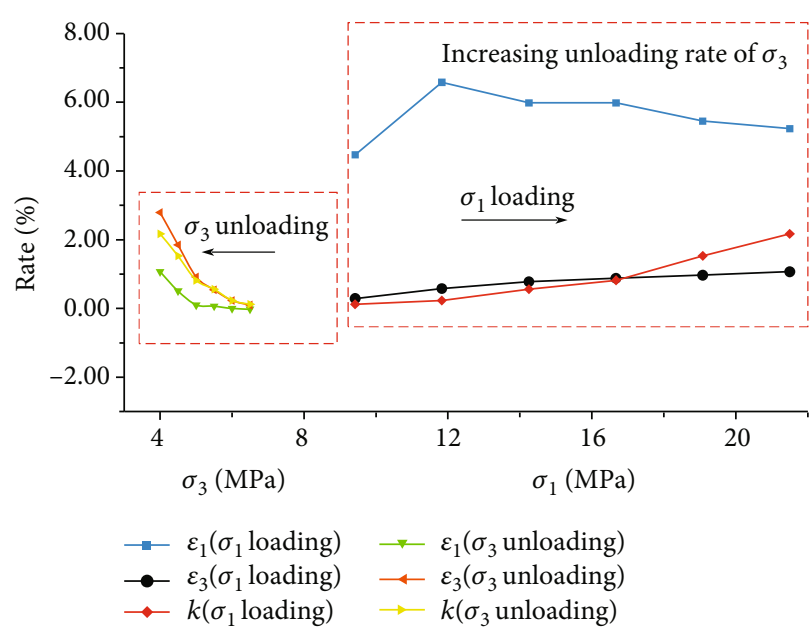

(a) Rate of change of strain and permeability of raw coal specimen S5

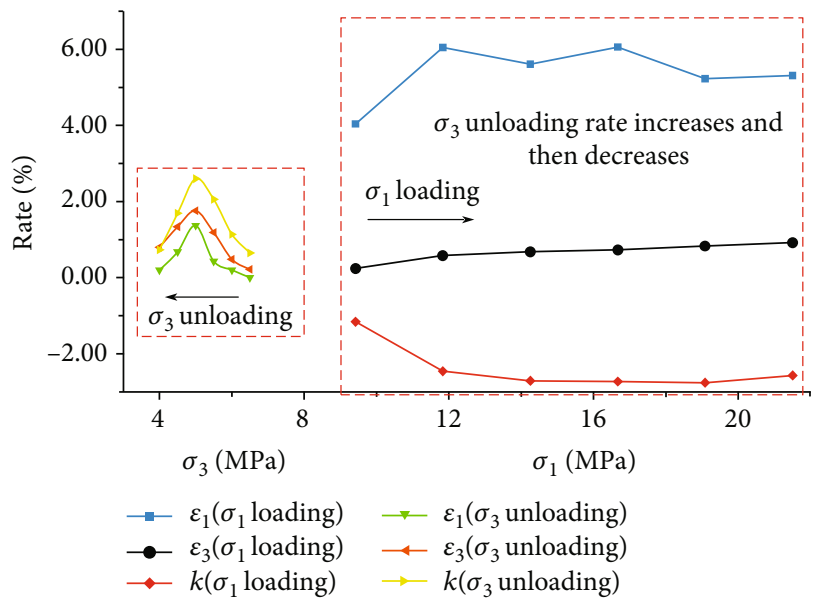

(c) Rate of change of strain and permeability of raw coal specimen S7

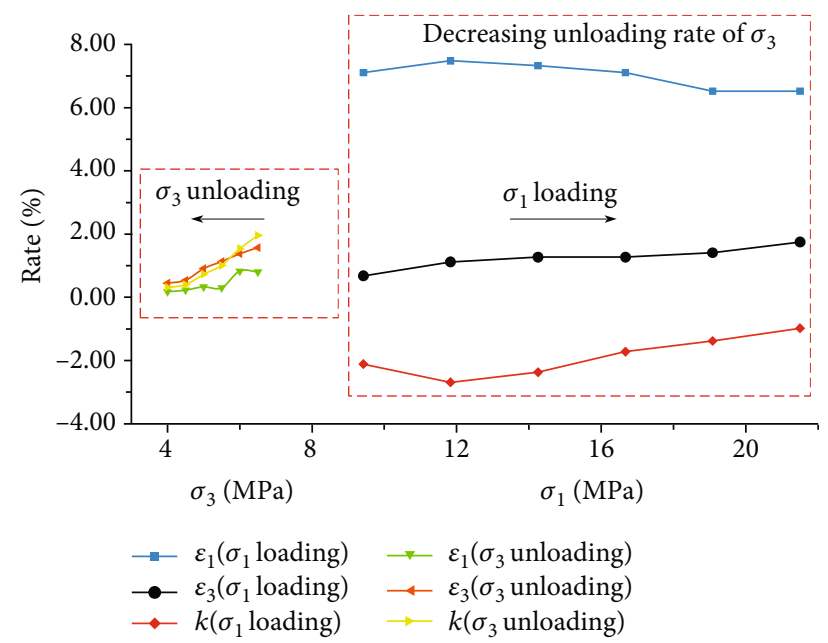

(b) Rate of change of strain and permeability of raw coal specimen S6

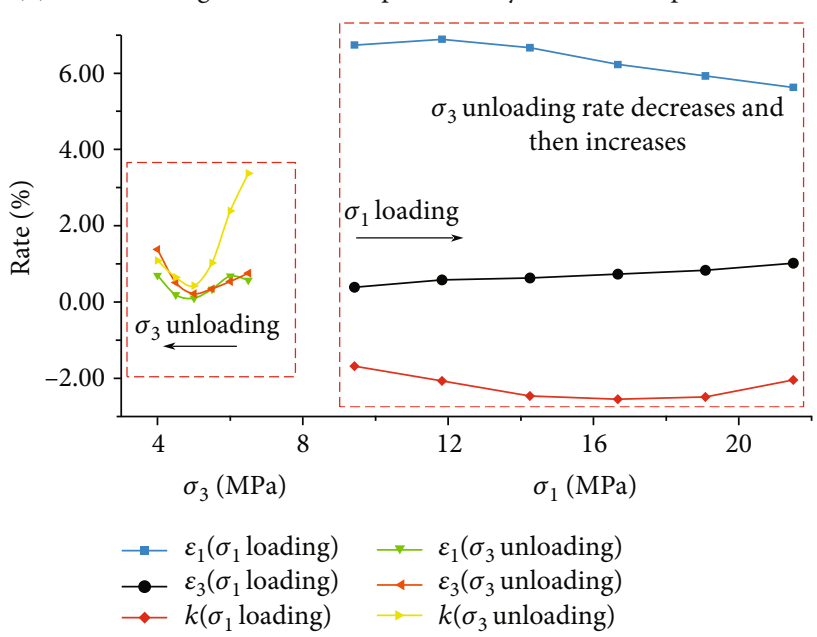

(d) Rate of change of strain and permeability of raw coal specimen $\mathrm{S8}$

FIGURE 7: Rate of change of strain and permeability of raw coal under variable confining pressure unloading rate.

(5)-(7) are used to calculate the rate of change of $\varepsilon_{1}, \varepsilon_{3}$, and $k$ with time.

$$
\begin{aligned}
& \varepsilon_{1}{ }^{\prime}=\frac{d \varepsilon_{1}}{d t}, \\
& \varepsilon_{3}{ }^{\prime}=\frac{d \varepsilon_{3}}{d t}, \\
& k^{\prime}=\frac{d k}{d t},
\end{aligned}
$$

where $\varepsilon_{1}{ }^{\prime}, \varepsilon_{3}{ }^{\prime}$, and $k^{\prime}$ are the rate of change of axial strain, radial strain, and permeability with time, respectively, under variable loading rates at alternate loading and unloading stages. The calculation results are shown in Figure 6. The $\varepsilon_{1}{ }^{\prime}$ and $k^{\prime}$ of raw coal in the increasing stage of axial stress are greater than the change values in the confining pressure unloading stage, but $\varepsilon_{3}{ }^{\prime}$ is less than the increased value in the confining pressure during unloading stage. In the stage of axial stress loading, $\varepsilon_{1}{ }^{\prime}, \varepsilon_{3}{ }^{\prime}$, and $k^{\prime}$ show the same change rule as the loading rate. As the loading rate increases, $\varepsilon_{1}{ }^{\prime}, \varepsilon_{3}{ }^{\prime}$
, and $k^{\prime}$ gradually rise, and they always show the relationship of $\varepsilon_{1}{ }^{\prime}>k^{\prime}>\varepsilon_{3}{ }^{\prime}$; as the loading rate decreases, $\varepsilon_{1}{ }^{\prime}, \varepsilon_{3}{ }^{\prime}$, and $k^{\prime}$ first decrease and then increase; as the loading rate first increases and then decreases or first decreases and then increases, $\varepsilon_{1}{ }^{\prime}, \varepsilon_{3}{ }^{\prime}$, and $k^{\prime}$ show the same change rule with it. At the stage of identical confining pressure unloading rate, $\varepsilon_{1}{ }^{\prime}, \varepsilon_{3}{ }^{\prime}$, and $k^{\prime}$ all show the variation trend of increasing, and $\varepsilon_{3}{ }^{\prime}$ is always greater than $\varepsilon_{1}{ }^{\prime}$ and $k^{\prime}$.

\subsection{Effects of Variable Confining Pressure Unloading Rate on} the Rate of Change of Strain and Permeability. To explore the evolution law of strain and permeability of raw coal specimen under variable confining pressure unloading rate, formulas (5)-(7) are used to calculate the rate of change of $\varepsilon_{1}{ }^{\prime}, \varepsilon_{3}{ }^{\prime}$, and $k^{\prime}$ with time, and the calculated results are shown in Figure 7. $\varepsilon_{1}{ }^{\prime}, \varepsilon_{3}{ }^{\prime}$, and $k^{\prime}$ show the same change rule with confining pressure unloading rate. As the unloading rate associated with confining pressure increases, $\varepsilon_{1}{ }^{\prime}$, $\varepsilon_{3}{ }^{\prime}$, and $k^{\prime}$ all continuously increase; as the unloading rate decreases, $\varepsilon_{1}{ }^{\prime}, \varepsilon_{3}{ }^{\prime}$, and $k^{\prime}$ all gradually decrease; as the unloading rate first decreases and then increases or first 
increases and then decreases, $\varepsilon_{1}{ }^{\prime}, \varepsilon_{3}{ }^{\prime}$, and $k^{\prime}$ show the same variation with it. During the unloading stage associated with confining pressure, $\varepsilon_{1}{ }^{\prime}$ always keeps minimum. $\varepsilon_{1}{ }^{\prime}>\varepsilon_{3}{ }^{\prime}>$ $k^{\prime}$ is always maintained in the loading process with the same axial pressure loading rate, and $\varepsilon_{1}{ }^{\prime}$ is always greater than that in the unloading stage associated with confining pressure. The variation amplitudes of $\varepsilon_{1}^{\prime}$ and $k^{\prime}$ are not significant. $\varepsilon_{3}{ }^{\prime}$ always and continuously increases, but the variation amplitude is also not significant.

\section{Conclusions}

In this paper, a study is conducted on the effects of variable axial pressure loading rate and variable confining pressure unloading rate on the strain behavior and seepage characteristics of raw coal under alternate loading and unloading of axial pressure and confining pressure. The main conclusions are as follows:

As axial stress increases, axial strain $\varepsilon_{1}$ decreases, radial strain $\varepsilon_{3}$ increases, and permeability $k$ decreases. When confining pressure decreases, $\varepsilon_{1}{ }^{\prime}, \varepsilon_{3}{ }^{\prime}$, and $k^{\prime}$ increase.

With the loading of axial stress and the unloading of confining pressure, the variation amplitudes of $\varepsilon_{1}{ }^{\prime}, \varepsilon_{3}{ }^{\prime}$, and $k^{\prime}$ values reduce gradually. During axial stress loading, the rise in the amplitude of $\varepsilon_{1}$ is larger than that of $\varepsilon_{3}$ and the reduction in the amplitude of $k$, indicating that $\varepsilon_{1}$ is more sensitive to axial stress than $\varepsilon_{3}$ and $k$.

During unloading of confining pressure, the increase rate of $\varepsilon_{3}$ is larger than that of $\varepsilon_{1}$ and $k$; also, $\varepsilon_{3}$ showed a high sensitivity to confining pressure.

In the stage of axial stress loading and confining pressure unloading, the evolution law of deformation and permeability parameters is basically consistent with the change in loading and unloading rate.

\section{Data Availability}

The data used to support the findings of this study have not been made available because research project is in progress.

\section{Conflicts of Interest}

The authors declare no conflict of interest.

\section{Acknowledgments}

This study was supported by the Research Fund of State and Local Joint Engineering Laboratory for Gas Drainage \& Ground Control of Deep Mines (Henan Polytechnic University) (No. SJF202004) and by the Huai'an Natural Science Research Program (HAB202154).

\section{References}

[1] L. Yuan, "Strategic thinking of simultaneous exploitation of coal and gas in deep mining," Journal of China Coal Society, vol. 41, no. 1, pp. 1-6, 2016.

[2] H. Xie, "Research review of the state key research development program of China: deep rock mechanics and mining theory,"
Journal of China Coal Society, vol. 44, no. 5, pp. 1283-1305, 2019.

[3] Y. Zou and B. Cheng, "Experimental study on mapping mechanism of loading process of rock and coal and gas permeability," Coal Science and Technology, vol. 47, no. 11, pp. 224-230, 2019.

[4] Z. Meng, B. Wang, X. Xie, Y. Xue, and X. Du, "Mechanical properties of coal deformation and its influence on permeability," Journal of China Coal Society, vol. 37, no. 8, pp. 13421347, 2012.

[5] Y. Geng, "Mechanism of compound dynamic disaster and integrated prevention technology in deep mine," Safety in Coal Mines, vol. 47, no. 11, pp. 73-76, 2016.

[6] Y. Cheng, J. Fu, and Q. Yu, "Development of gas extraction technology in coal mines of China," Journal of Mining and Safety Engineering, vol. 26, no. 2, pp. 127-139, 2009.

[7] C. Jiang, Y. Gao, S. Chen, and S. Lü, "Study on classification and identification indexes about gas dynamical disaster in coal mine," Journal of China Coal Society, vol. 32, no. 2, pp. 159162, 2007.

[8] H. Lan, D. Chen, and D. Mao, "Current status of deep mining and disaster prevention in China," Coal Science and Technology, vol. 44, no. 1, pp. 39-46, 2016.

[9] M. Duan, C. Jiang, X. Guo, K. Yang, X. Zhang, and H. Ma, "Experimental study on mechanical and damage characteristics of coal under cyclic true triaxial loading," Chinese Journal of Rock Mechanics and Engineering, vol. 40, no. 6, pp. 11101118, 2021.

[10] X. Li and B. Lin, "Status of research and analysis on coal and gas outburst mechanism," Coal Geology \& Exploration, vol. 38, no. 1, pp. 7-13, 2010.

[11] G. Yin, B. Ma, C. Liu, M. Li, and S. Yin, "Effect of loading and unloading rates on mechanical properties and energy characteristics of sandstone under true triaxial stress," Journal of China Coal Society, vol. 44, no. 2, pp. 454-462, 2019.

[12] H. Xie, H. Zhou, J. Liu et al., "Mining-induced mechanical behavior in coal seams under different mining layouts," Journal of China Coal Society, vol. 36, no. 7, pp. 1067-1074, 2011.

[13] Y. Lü and H. Qin, "Investigation into mechanical responses and energy dissipation properties of coal containing methane to confinement unloading," Journal of China Coal Society, vol. 37, no. 9, pp. 1505-1510, 2012.

[14] H. Zhao, D. Zhang, G. Bian, and W. Li, "Deformation and permeability of sandstone at different cycling loading-unloading rates," Chinese Journal of Engineering, vol. 39, no. 1, 140 pages, 2017.

[15] H. Wang, P. Fan, M. Wang, W. Li, and Y. Qian, "Influence of strain rate on progressive failure process and characteristic stresses of red sandstone," Rock and Soil Mechanics, vol. 32, no. 5, pp. 1340-1346, 2011.

[16] L. Jia, B. Li, J. Li, Z. Gao, J. Xu, and X. Wu, "Study on the permeability evolution mechanism of gas-coal production stage under the influence of temperature," Chinese Journal of Rock Mechanics and Engineering, vol. 41, pp. 1-15, 2021.

[17] X. Bai, D. Wang, B. Li, D. Zhang, H. Li, and F. Ren, "Permeability model of damaged coal under triaxial stress loadingunloading," Chinese Journal of Rock Mechanics and Engineering, vol. 40, no. 8, pp. 1536-1546, 2021.

[18] X. Li, S. Chen, S. Liu, and Z. Li, “AE waveform characteristics of rock mass under uniaxial loading based on Hilbert-Huang transform," Journal of Central South University., vol. 28, no. 6, pp. 1843-1856, 2021. 
[19] Z. Zhang, C. Zhong, K. Xue, and Q. Qin, "Mechanical mechanism of pore fluid on coal dynamic disasters under cyclic loading," Journal of China Coal Society, vol. 46, no. 2, pp. 466-476, 2021.

[20] B. Li, Z. Gao, K. Yang et al., "Study on coal adsorptionpermeability model under the coupling of temperature and pore pressure," Chinese Journal of Rock Mechanics and Engineering, vol. 39, no. 4, pp. 668-681, 2020.

[21] G. Yin, W. Li, J. Xu et al., "Development and application of fracturing and seepage experimental system for multiphysical field and multiphase coupling of porous media," Chinese Journal of Rock Mechanics and Engineering, vol. 35, no. S1, pp. 2853-2861, 2016. 